\title{
Testing International Momentum Strategies between Chinese and Australian Financial Markets
}

\author{
Santosh Mon Abraham ${ }^{1}$ \\ ${ }^{1}$ Curtin University, Bentley, Western Australia, Australia \\ Correspondence: Santosh Mon Abraham, Curtin University, 218 Dawson Avenue, Forrestfiled, WA 6058, Australia. \\ Tel: 61-8-9453-1071. E-mail: Santosh.abraham@student.curtin.edu.au \\ Received: October 24, 2013 \\ doi:10.5430/ijfr.v5n1p1 \\ Accepted: November 11, 2013 \\ Online Published: January 10, 2014 \\ URL: http://dx.doi.org/10.5430/ijfr.v5n1p1
}

\begin{abstract}
This paper tests international momentum effects between Chinese Shanghai Composite Index and Australian resource stocks. If markets were efficient, there would be no profits from momentum strategies. Two momentum strategies are examined; index tracking and enhanced indexing. The enhanced indexing strategy is more profitable than the index tracking strategy, although the index tracking strategy had a higher Sharpe Ratio. Small capitalised stocks exhibit strong momentum effects. Using a newly developed partial adjustment model, support is provided for Chan et al (1996) who demonstrate that under-reaction to economic news explains momentum profits and Rouwenhorst (1998) who finds evidence of momentum effects in emerging countries.
\end{abstract}

Keywords: momentum strategies, statistical arbitrage, efficient markets

\section{Introduction}

Momentum strategies involve buying past winners and selling past losing stocks. Jegadeesh and Titman (1993) find that over six-month period a momentum strategy in NYSE/AMEX stock exchanges earns approximately one per cent per month. Rouwenhorst (1998) studied a sample of 12 European countries over the period from 1980 to 1995 and found similar results to those of Jegadeesh and Titman (1993). Rouwenhorst (1997) studied a sample of 20 emerging markets and found momentum effects led to abnormal profits (Hong et al, 2000).

There is a gap in the literature in that whilst international momentum effects have been studied by Rouwenhorst (1998) and others, there has been no research conducted on international momentum effects that involve the joint indexing strategies between and index in one country and stocks in another country. China and Australia were chosen because of the close economic and trading relationship between the two countries. China's demand for Australian resources and energy exports has resulted in a trade surplus for Australia. Figure 1 shows the growth in exports due to Chinese demand.

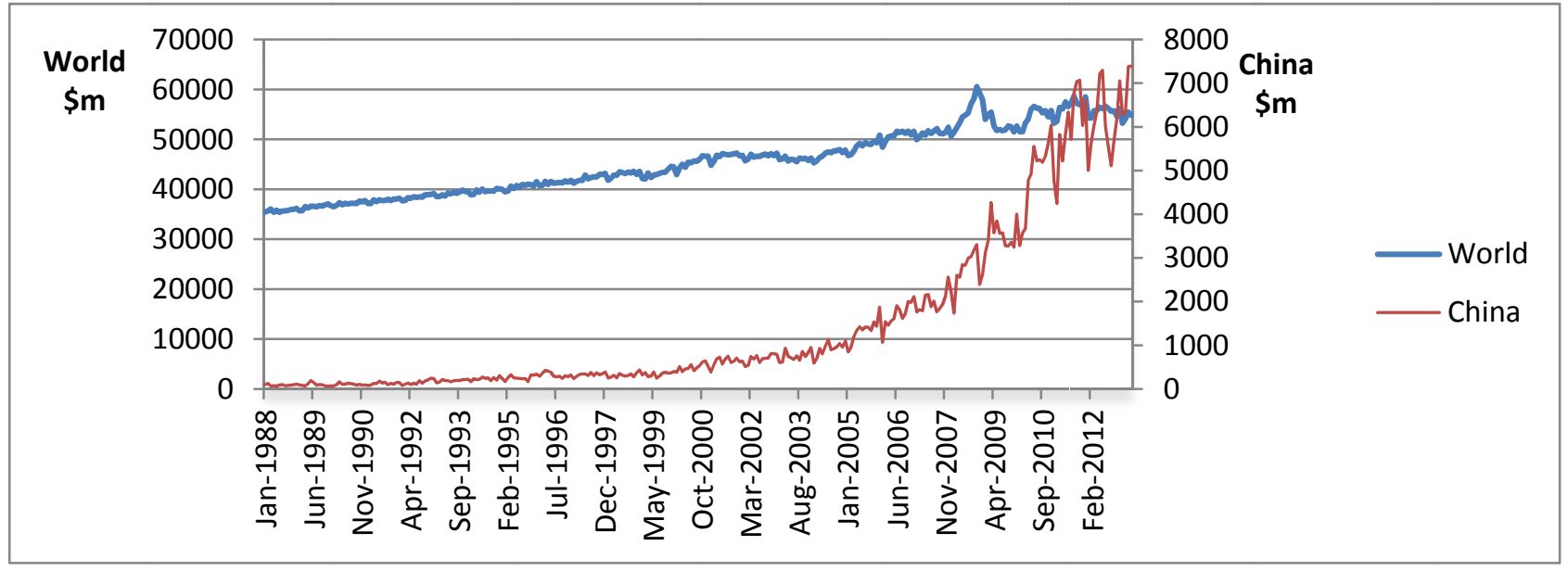

Figure 1. The Australian exports 1988-2013

Source: ABS Catalogue 53680.14a 
The cause of momentum effects is disputed. De Long et al (1990) state prices initially over-react to news about fundamentals and then subsequently over-react further. Momentum can also be said to be a result of under-reaction. Barberis et al (1998), state there is a representative investor who suffers from a conservatism bias that prevents him from updating his beliefs sufficiently when he observes new public information. Conrad and Kaul (1998) proposed a risk-based interpretation of momentum. Hong and Stein (1999) emphasise heterogeneities across investors who observe different pieces of private information at different stages. Hong and Stein assume: (1) firm-specific information diffuses gradually across investors; and (2) investors cannot extract information from stock prices. These assumptions generate under-reaction (Hong et al, 2000).

Since information about small firms gets out more slowly, investors face fixed costs of information acquisition, and thus choose to devote more effort to studying stocks in which they can take large positions. Chan et al (1996) demonstrate that momentum strategies are profitable even after accounting for post-earnings-announcement drift (Bernard and Thomas $(1989,1990)$, Bernard (1992)). Thus momentum may reflect the adjustment of stock prices to information that is not publicly available to all investors at once (Hong et al, 2000).

Merton (1987) and Grossman and Miller (1988) argue that market making or arbitrage capacity may be less in small-capitalization stocks. Less arbitrage means that any diffusion will have a bigger impact in small stocks, leading us to overstate the importance of gradual information flow as the specific mechanism at work. This is a limitation of the study.

\section{Review of Related Literature}

Efficient market hypothesis has been violated by the performances of stock returns in some studies. The prospect theory of Kahnman and Tversky (1979), Jegadeesh and Titman (1993) proposes a model of momentum to examine market efficiency. It found that stock prices are predictable under the momentum model. The extension of prospect theory by Daniel and Titman (1999) on over-confidence also indicates that certain stocks could generate greater over-confidence among investors, resulting in a stronger momentum effect. Other studies argue that momentum returns only appear in a bullish market rather than in a bearish market.

As previously mentioned, Jegadeesh and Titman (1993) find that over three to twelve months past winners continue to out-perform past losers by about one per cent per month and that stock prices under-react to economic information. Chan et al (1996) demonstrate that stock prices respond sluggishly to earnings news and that most of the momentum effect is focused on subsequent earnings announcements.

Hong et al (1998) demonstrate that under-reaction of stock prices is reliant upon analyst coverage. In examining the profitability of international equities Rouwenhorst (1997) shows that momentum strategies are profitable for equities in 12 European countries, and Rouwenhorst (1998) also states that emerging market stocks show evidence of momentum effects.

The returns from momentum strategies outlined in Jegadeesh and Titman (1993) and further by Jegadeesh and Titman (2001), challenge to market efficiency. These findings are robust as confirmed by Rouwenhorst (1998) and Griffin, Ji, and Martin (2003) who find momentum in international markets. Fama and French (1993) state market, value, and size factors cannot account for momentum returns. Grundy and Martin (2001) state firm-specific factors are responsible for momentum.

However, O'Hara (2003) states that price momentum demonstrate the need to incorporate asymmetric information into asset pricing. In Wang (1994), informed investors engage in financial transactions by buying stocks because of their private information or because of changes in their investment opportunities. These lead to different return dynamics since uninformed investors cannot immediately identify the private information. Learning from the behaviours of informed investors allows uninformed investors to update their initial assessment of informed trading and they update their cash-flow expectations and imitate the earlier trades of informed investors. In this way uninformed investors gradually become informed and influence prices in a manner that causes momentum.

Barberis et al (1998) and Daniel et al (1998) demonstrate that momentum in stock prices may be the outcome of behavioural biases in the presence of limits to arbitrage. Such mis-pricings attributed to behavioural biases may be corrected in the long-run, which generates the crucial prediction that short-term momentum is followed by long-term contrarian effects. Momentum strategies involve stocks with high transaction costs (Grundy and Martin (2001), Lesmond, Schill, and Zhou (2004), as well as Korajczyk and Sadka (2004)). Liquidity also depends on the degree of asymmetric information (e.g. Kyle (1985)).

The method of statistical arbitrage frees us from getting benchmark return via an equilibrium model suffering the joint hypothesis criticism. This paper examines the profitability of momentum strategies formed based on past 
returns of Australian resource stocks and the Chinese CSC index. Our results indicate evidence of momentum profits that are statistically and economically significant.

\section{Partial Adjustment Model}

The partial adjustments model (PAM) assumes there is a long-run equilibrium which is the "target" return (the expected stock return in an efficient market). The long-run equilibrium equation is given by the single-index model:

$$
R_{t}^{*}=a+\beta R_{m}+e
$$

Where $\mathrm{R}_{\mathrm{t}}$ is the target return; a is the excess return; $\mathrm{B}$ is the sensitivity of the stock to the market, $\mathrm{R}_{\mathrm{m}}$ is the market return; and $\mathrm{e}$ is the residual.

Like the model of Amihud and Mendelson (1987), the impact from noise trading is the difference between the fundamental return and the observed return.

The following hypothesis known as the PAM is postulated:

$$
\begin{gathered}
R_{t}-R_{t-1}=\delta\left(R_{t}^{*}-R_{t-1}\right) \\
R_{t}-R_{t-1}=\delta\left(\left(a+\beta R_{m}+e\right)-R_{t-1}\right) \\
R_{t}=\delta a+\delta \beta R_{m}+(1-\delta) R_{t-1}+\delta e \\
R_{t}=\delta a+\delta \beta R_{m}+(1-\delta) \beta R_{m_{t-1}}+\delta e
\end{gathered}
$$

Where $\mathrm{R}_{\mathrm{t}}$ is the return in time period $\mathrm{t}, \mathrm{R}_{\mathrm{t}-1}$ is the return in time period $\mathrm{t}-1, \delta$ is the speed of adjustment coefficient and e is the error term $\mathrm{E}[\mathrm{u}]=0$ and $\mathrm{E} \sim \mathrm{N}\left(0, \sigma^{2}\right)$. When $\delta$ equals 0 there is no adjustment, when $\delta$ equals 1 there is full adjustment and the market is efficient, when $\delta$ is greater than 1 there is an over-reaction to economic information and when $\delta$ lies between 0 and 1 there is partial adjustment or under-reaction to economic information.

There should be no opportunity to use information gathered in period t- 1 to provide a correct assessment of the expected return. The information available at $\mathrm{t}-1$, the time series of past returns, should not be able to be used to correctly determine the expected return. By using past information in this way makes this approach a test of weak form market efficiency.

The first step is to calculate the alpha (excess return) and beta (systematic risk) by regression the stock's return against the market return. The beta is multiplies by the market return and added to alpha. The proxy used for the lagged return is $\beta \mathrm{R}_{\mathrm{m}(\mathrm{t}-1)}$. The stochastic explanatory variable $\mathrm{R}_{\mathrm{t}-1}$ may be correlated with the error term, which would make the OLS estimator biased and inconsistent so that the estimates would not approximate their true population values. This correlation can be removed by finding a suitable proxy for $R_{t-1}$. Such a proxy is $\beta R_{m(t-1)}$.

The single-index model is used in the PAM instead of a multi-factor model because the object of the PAM is to calculate the speed of adjustment coefficient. A multi-factor model would introduce too many terms in the PAM and would lead to difficulties in finding an appropriate proxy for $\mathrm{R}_{\mathrm{t}-1}$.

\section{Equity Indexing}

Equity indexing is the most popular form of passive investment, aiming to replicate the risk and return characteristics of a benchmark, usually a wide stock market index. Traditional capital market theory states that the market portfolio offers the highest level of return per unit of risk and the only way investors can beat the market is by taking greater risks. Additionally, active management has been shown to under-perform compared to its passive alternative due to transaction costs and administration fees, mostly in bull, but also in bear markets.

A passive investment approach implies that the stocks underlying an index, are bought and held. There should be no change regarding the underlying composition of assets of an index except for technical reasons, such as initial public offerings (IPOs), mergers, capital increases, changes in the free float, etc. Index tracking is based on selective types of indices and represents a form of active investment management. Such indices are conformable to momentum strategies. The timing and methods implied by the selection and rebalancing rules of the indices are consistent short-run momentum strategies which consider the continuation effect of recent winners and losers or dynamic trading with respect to reference levels, such as stop-loss strategies. Based on the aforementioned literature the issues to be answered are as follows:

- Are there profits to be made from the index tracking strategy?

- Does the index tracking strategy closely track the CSC index?

- Are there profits to be made from the enhanced indexing strategy? 
- Does the enhanced indexing strategy closely track the CSC index?

- Is the index tracking strategy more profitable than the enhanced indexing strategy?

- Does the index tracking strategy have a higher Sharpe Ratio than the enhanced indexing strategy?

\section{Data and Sample}

The sample consists of 533 weekly observations from 1 Jan 2003 to 1 Mar 2013 of the Chinese Shanghai Composite Index and 33 Australian Resource stocks. The Australian stocks were tested for a cointegrating relationship with the CSC Index and 13 stocks had such a relationship. All variables were converted to natural logarithms and standardised. The financial data was collected from Yahoo Finance.

\section{Methodology}

\section{Index Tracking Model}

The portfolio holdings in each of the stocks selected are estimated based on ordinary least squares coefficients of the co integration equation that regresses the index log price on the portfolio stocks log prices over a given calibration period prior to the portfolio's construction moment. The log transformation is applied to produce a more homogenous series.

$$
\log \left(C S C_{t}\right)=a_{0}+\sum_{k=1}^{n} a_{k} \cdot \log P_{k t}+e_{t}
$$

The index is the CSC Index $P_{K, t}$ is the price of the Australian stock $P_{K}$ at time $t$. If the series CSC Index is co integrated with $\mathrm{P}_{\mathrm{K}, \mathrm{t}}$ the residual series (the tracking error) will be stationary. The use of log prices means that the tracking error is in return format and the $\alpha_{K}$ coefficients are the portfolio weights. The weights will be normalised to sum up to one to give the percentage weight of each selected stock in the index tracking portfolio. The index tracking portfolio daily returns are computed as the weighted sum of the daily returns of its constituent stocks. The residuals of each co integration regression were tested for stationarity following the Engle-Granger methodology for co integration testing. The Engle-Granger criterion of minimum variance is important. The Engle-Granger small sample bias is not problematic as we have a large sample.

The data are transformed in to logarithms and standardised according to the following formula:

$$
\text { Standardised Price }=\frac{\text { Price }- \text { Mean Price }}{\text { Standard Deviation of Price }}
$$

\section{Enhanced Indexing Model}

Having constructed a simple tracking strategy, the study will replicate 'plus' and 'minus' benchmarks which are constructed by adding to/subtracting from the benchmark returns an annual excess return of $\mathrm{x} \%$, uniformly distributed to daily returns.

$$
\log \left(\text { CSC }_{t} \text { Plus }_{t}\right)=a_{0}+\sum_{k=1}^{n} a_{k} \cdot \log P_{k t}+e_{t}
$$

The CSC Plus index is devised as a benchmark for the long portfolio.

$$
\log \left(\text { CSC }_{t} \text { Minus }_{t}\right)=a_{0}+\sum_{k=1}^{n} a_{k} \cdot \log P_{k t}+e_{t}
$$

The CSC Minus index is devised as a benchmark for the short portfolio.

The tracking error and the Sharpe ratio are calculated for the index tracking and enhanced indexing portfolios. The tracking error is a measure of how closely a portfolio follows the index to which it is benchmarked.

$$
\omega=\sqrt{\operatorname{Var}\left(r_{p}-r_{b}\right)}
$$

The Sharpe Ratio measures the performance of the portfolio.

$$
S R=\frac{\text { Return-Risk FreeRate }}{\text { Standard Deviation }}
$$




\section{Results}

Table 1 shows the Phillips-Perron unit root tests for the Australian resources stocks in this sample.

Table 1. Phillips-Perron unit root tests for Australian resource stocks

\begin{tabular}{|c|c|c|}
\hline STOCK & LEVELS & FIRST DIFFERENCES \\
\hline BHP.AX & -1.789949 & -19.4243 \\
\hline RIO.AX & -0.72826 & -20.93433 \\
\hline NCM.AX & -0.669432 & -22.78356 \\
\hline AAI.AX & -1.052124 & -18.58073 \\
\hline BSL.AX & 1.223907 & -19.4238 \\
\hline SGM.AX & -1.169613 & -17.63204 \\
\hline RRL.AX & -2.173183 & -19.88612 \\
\hline AGG.AX & -1.675569 & -19.58296 \\
\hline OZL.AX & -2.49902 & -18.6707 \\
\hline PNA.AX & -0.607648 & -21.84064 \\
\hline OGC.AX & -1.292835 & -20.57792 \\
\hline ARI.AX & -1.51602 & -18.91468 \\
\hline LYC.AX & -1.237187 & -22.61299 \\
\hline EVN.AX & -1.425457 & -21.04726 \\
\hline IGO.AX & -1.820467 & -21.80357 \\
\hline SIR.AX & -1.991451 & -18.23804 \\
\hline RSG.AX & -1.236536 & -20.70854 \\
\hline SPH.AX & -1.768171 & -19.82232 \\
\hline CDU.AX & -2.514544 & -19.26155 \\
\hline SDL.AX & 0.403509 & -22.6629 \\
\hline WSA.AX & -2.36573 & -19.55769 \\
\hline KCN.AX & -1.202095 & -22.47076 \\
\hline SBM.AX & -0.662528 & -21.66665 \\
\hline MGX.AX & -1.669223 & -18.60804 \\
\hline IGR.AX & 0.132306 & -22.08376 \\
\hline IRN.AX & -2.494256 & -20.80207 \\
\hline GDO.AX & -0.854242 & -20.98874 \\
\hline AQP.AX & -1.276417 & -17.60174 \\
\hline GBG.AX & -1.453913 & -20.91228 \\
\hline MDL.AX & 0.044004 & -19.81493 \\
\hline IMD.AX & -1.231399 & -20.09475 \\
\hline GRR.AX & -2.468325 & -17.58637 \\
\hline TRY.AX & -3.314246 & -15.63189 \\
\hline
\end{tabular}

Note: The critical values are $-3.442460(1 \%) ;-2.866774(5 \%) ;-2.569618(10 \%)$.

All Australian resource stocks in the sample were non-stationary in levels and stationary in first differences. 
Table 2 shows the results of the Index Tracking and Enhanced Indexing strategies.

Table 2. Results of the index tracking and enhanced indexing strategies

\begin{tabular}{lllll}
\hline & Index & 5 Per cent & 10 per cent & 15 per cent \\
\hline A/Return & $10.35 \%$ & $13.57 \%$ & $13.77 \%$ & $13.97 \%$ \\
TE & $0.40 \%$ & $0.69 \%$ & $0.70 \%$ & $0.72 \%$ \\
RF & $4.99 \%$ & $4.99 \%$ & $4.99 \%$ & $4.99 \%$ \\
SD & 0.61 & 1.33 & 1.36 & 1.39 \\
SR & $8.83 \%$ & $6.46 \%$ & $6.45 \%$ & $6.44 \%$ \\
\hline
\end{tabular}

The Index is the CSC benchmark. 5 per cent is the Plus 5\% and Minus $5 \%$ portfolio, 10 per cent is the Plus $10 \%$ and Minus $10 \%$ portfolio and 15 per cent is the Plus $15 \%$ and Minus $15 \%$ portfolio. A/Return is the annual return, TE is the tracking error, RF is the average risk-free rate, SD is the standard deviation and SR is the Sharpe ratio. Table 2 shows that the index tracking strategy has an annual return of $10.35 \%$ and a tracking error (TE) of $0.4 \%$. Plus Minus $5 \%$ portfolio has an annual return of $13.57 \%$ and a TE of $0.69 \%$. Plus Minus $10 \%$ portfolio has an annual return of $13.77 \%$ and a TE of $0.70 \%$. Plus Minus $15 \%$ portfolio has an annual return of $13.97 \%$ and a TE of $0.72 \%$. However, the index tracking portfolio has the highest Sharpe ratio of $8.83 \%$.

Figure 2 shows the efficient frontier for the index tracking portfolio and the three enhanced indexing portfolios.

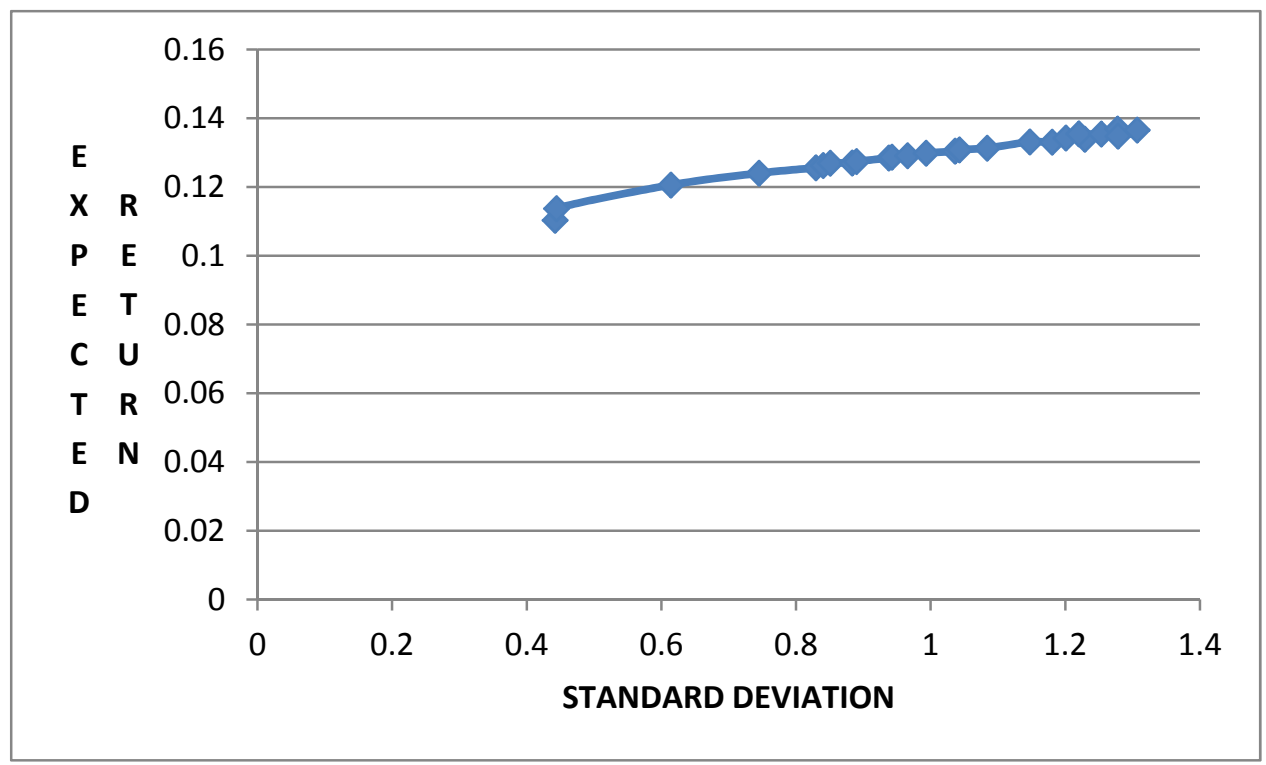

Figure 2. The Efficient frontier for index tracking and enhanced indexing portfolios

The Sharpe ratio was maximised to find the optimal portfolio. It was determined that the portfolio consisted of going long in the index tracking portfolio $(64.46 \%)$ and the Plus-Minus $5 \%$ portfolio $(210 \%)$ and going long in the Plus-Minus $10 \%$ portfolio (202\%) and going short in the Plus-Minus $15 \%$ portfolio (376\%). 
Table 3 shows the diagnostics of the PAM.

Table 3. The diagnostics of the partial adjustment model

\begin{tabular}{lrrrr}
\hline STOCK & \multicolumn{1}{c}{ COEFF } & t-Stat & \multicolumn{1}{l}{ R-SQR } & \multicolumn{1}{l}{ DW } \\
\hline NCM.AX & -0.56368 & -6.68554 & 0.016583 & 2.426353 \\
OGC.AX & -0.07514 & -1.75907 & 0.001275 & 1.990348 \\
MDL.AX & -0.04556 & -0.50602 & 0.000107 & 1.983126 \\
GDO.AX & -0.04175 & -0.10994 & 0.03068 & 1.436451 \\
KCN.AX & -0.0306 & -0.66951 & 0.000281 & 1.975596 \\
AGG.AX & -0.01143 & -0.7894 & 0.000245 & 2.262396 \\
AAI.AX & -0.00767 & -0.51201 & 0.002521 & 2.108659 \\
SBM.AX & -0.0073 & -0.13522 & 0.002402 & 2.442574 \\
CDU.AX & -0.00323 & -0.07279 & 0.000717 & 1.983054 \\
RRL.AX & -0.00172 & -0.05083 & 0.001636 & 2.023806 \\
IGO.AX & 0.001197 & 0.038107 & 0.002755 & 2.045536 \\
SPH.AX & 0.007957 & 0.203515 & 0.000298 & 2.137731 \\
BHP.AX & 0.008888 & 0.914902 & 0.016881 & 2.092183 \\
MGX.AX & 0.010172 & 0.476272 & 0.005139 & 2.000023 \\
RSG.AX & 0.010207 & 0.278675 & 0.000342 & 2.02444 \\
IGR.AX & 0.010456 & 0.219221 & 0.002899 & 2.213796 \\
LYC.AX & 0.011292 & 0.403605 & 0.004726 & 2.129354 \\
SDL.AX & 0.014483 & 0.313774 & 0.000354 & 1.998599 \\
PNA.AX & 0.014727 & 0.50289 & 0.001281 & 2.005987 \\
ARI.AX & 0.01512 & 0.899238 & 0.008397 & 2.108659 \\
AQP.AX & 0.019917 & 1.183306 & 0.016273 & 1.945965 \\
BSL.AX & 0.022004 & 0.903593 & 0.001078 & 1.960833 \\
GBG.AX & 0.023421 & 0.927618 & 0.006369 & 2.132077 \\
TRY.AX & 0.030744 & 1.726071 & 0.006125 & 1.947409 \\
OZL.AX & 0.044024 & 1.962422 & 0.013189 & 2.066952 \\
SGM.AX & 0.044598 & 0.355612 & 0.002634 & 2.07253 \\
IMD.AX & 0.060852 & 2.052789 & 0.006355 & 1.995376 \\
IRN.AX & 0.06988 & 1.460731 & 0.00259 & 2.126806 \\
EVN.AX & 0.083956 & 2.025263 & 0.002926 & 2.155215 \\
RRR.AX & 0.102273 & 2.419297 & 0.006435 & 1.96512 \\
WIOAX & 0.103299 & 1.374927 & 0.002429 & 2.10072 \\
\hline & 0.104174 & 2.051616 & 0.003681 & 2.044306 \\
0.104422 & 0.556284 & 0.000178 & 2.135877
\end{tabular}

Note: COEFF means coefficient; t-Stat means t-statistic; R-SQR means $\mathrm{R}^{2}$ coefficient; DW means Durbin-Watson Table 3 shows that there is little evidence of serial correlation in the diagnostic results and all coefficients of the variables are significant except for EVN.AX; GRR.AX; IMD.AX; NCM.AX; OZL.AX; SIR.AX. 
Table 4 shows the results of the speed of adjustment coefficients for the Australian resources stocks in the sample as derived from the partial adjustment model.

Table 4. The speeds of adjustments for the Australian resources stocks

\begin{tabular}{lrrr}
\hline STOCK & \multicolumn{1}{c}{ SPEED } & \multicolumn{1}{c}{ BETA } & \multicolumn{1}{c}{ MCAP(mil) } \\
\hline NCM.AX & 1.563677 & 1.153444 & $\$ 14,399.05$ \\
OGC.AX & 1.075138 & 1.194804 & $\$ 1,362.91$ \\
MDL.AX & 1.045558 & 1.066206 & $\$ 275.68$ \\
GDO.AX & 1.041748 & 0.810438 & $\$ 339.97$ \\
KCN.AX & 1.030601 & 0.991805 & $\$ 531.40$ \\
AGG.AX & 1.011431 & 1.425217 & $\$ 1,831.00$ \\
AAI.AX & 1.00767 & 0.133171 & $\$ 8,500.00$ \\
SBM.AX & 1.007299 & 1.45542 & $\$ 514.92$ \\
CDU.AX & 1.003231 & 0.299662 & $\$ 663.59$ \\
RRL.AX & 1.001721 & 0.268901 & $\$ 1,878.68$ \\
IGO.AX & 0.998803 & 0.838099 & $\$ 859.34$ \\
SPH.AX & 0.992043 & 1.794434 & $\$ 676.63$ \\
BHP.AX & 0.991112 & 0.63847 & $\$ 161,632.00$ \\
MGX.AX & 0.989828 & 1.083146 & $\$ 512.57$ \\
RSG.AX & 0.989793 & 1.435691 & $\$ 729.91$ \\
IGR.AX & 0.989544 & 0.876141 & $\$ 485.90$ \\
LYC.AX & 0.988708 & 0.996607 & $\$ 1,009.81$ \\
SDL.AX & 0.985517 & 1.530724 & $\$ 645.14$ \\
PNA.AX & 0.985273 & 1.334658 & $\$ 1,406.99$ \\
ARI.AX & 0.98488 & 0.566847 & $\$ 1,020.40$ \\
AQP.AX & 0.980083 & 0.555988 & $\$ 316.00$ \\
BSL.AX & 0.977996 & 0.76673 & $\$ 2,651.66$ \\
GBG.AX & 0.976579 & 0.788386 & $\$ 283.51$ \\
TRY.AX & 0.969256 & 1.808882 & $\$ 173.96$ \\
OZL.AX & 0.955976 & 1.33193 & $\$ 1,440.00$ \\
SGM.AX & 0.955402 & 1.680748 & $\$ 1,936.85$ \\
IMD.AX & 0.939148 & 0.942622 & $\$ 271.51$ \\
IRN.AX & 0.93012 & 0.980166 & $\$ 409.07$ \\
EVN.AX & 0.916044 & 0.786781 & $\$ 902.82$ \\
GRR.AX & 0.897727 & 0.819006 & $\$ 219.73$ \\
RIO.AX & 0.896701 & 1.335901 & $\$ 85,933.67$ \\
\hline & 0.895826 & 1.682214 & $\$ 788.42$ \\
SIR.AX & 0.895578 & 1.742187 & $\$ 574.78$ \\
\hline
\end{tabular}

There were 13 Australian resource stocks which were cointegrated with the CSC index; AQP, BHP, CDU., GBG, IGO. IMD, IRN, OGC, OZL, SBM, SIR, TRY and WSA. Of these 8 stocks under-reacted to economic information, three stocks BHP, CDU and IGO fully adjusted and were efficient and two stocks, OGC and SBM over-reacted to economic information. The results support the under-reaction hypothesis. All stocks were small cap stocks except for OGC and OZL which were mid-cap stocks, and BHP which was a large cap stock. 


\section{Discussion}

The results support Jegadeesh and Titman (1993) and Jegadeesh and Titman (2001) by finding evidence of momentum in Chinese and Australian markets, and confirm Rouwenhorst (1998) and Griffin, Ji, and Martin (2003) who find momentum in international markets. Fama and French (1998) state market, value, and size factors cannot account for momentum returns and Grundy and Martin (2001) state firm-specific factors are responsible for momentum. The findings of this paper are that size does indeed matter as most of the small cap stocks showed evidence of momentum effects.

O'Hara (2003) states that price momentum demonstrate the need to incorporate asymmetric information into asset pricing and Wang (1994) finds informed investors engage in financial transactions by buying stocks because of their private information or because of changes in their investment opportunities. These lead to different return dynamics since uninformed investors cannot immediately identify the private information. Learning from the behaviours of informed investors allows uninformed investors to update their initial assessment of informed trading and they update their cash-flow expectations and imitate the earlier trades of informed investors. In this way uninformed investors gradually become informed and influence prices in a manner that causes momentum. This paper finds evidence of heterogeneity in that generally large cap and medium cap stocks did not show evidence of momentum effects. In support of Hong et al (2000) it is concluded that large cap stocks have more analyst coverage than small cap stocks and thus trade close to their fundamental value. Whilst small cap stocks lack analyst coverage and are subsequently inefficient and are thus good candidates for an arbitrage strategy.

Barberis et al (1998) and Daniel et al (1998) demonstrate that momentum in stock prices may be the outcome of behavioural biases in the presence of limits to arbitrage. Such mis-pricings attributed to behavioural biases may be corrected in the long-run, which generates the crucial prediction that short-term momentum is followed by long-term contrarian effects. This paper finds that the mis-pricing may be the result of behavioural biases and that this mis-pricing is corrected by cointegration, resulting in a long-run equilibrium between Australian stocks and the CSC index which is efficient.

Lending support for the hypothesis of asymmetric information, this paper finds that information about small firms gets out more slowly which may be the result of responses to firm-specific information. Chan et al (1996) demonstrate momentum may reflect the adjustment of stock prices to information that is not publicly available to all investors at once (Hong et al, 2000). This paper confirms Rouwenhorst (1998) who demonstrates that momentum strategies are profitable in emerging markets.

\section{Conclusion}

The findings were that both index tracking and enhanced indexing strategies were profitable. Enhanced indexing was more profitable than index tracking; however, index tracking had a higher Sharpe ratio, a lower tracking error and significantly lower volatility. Of these momentum strategies, most Australian resource stocks which replicated the CSC index were small cap stocks and under-reacted to economic information. This supports the theories of Chan et al (1996) and Hong and Stein (1999). Small cap stocks seemed to gradually diffuse economic information. It is surmised that this is because small cap stocks do not have high levels of analyst coverage and are therefore inefficient. The results confirm that momentum stocks are profitable in an emerging country such as China and lend support to Rouwenhorst (1998).

\section{Acknowledgements}

Santosh Mon Abraham is supported by a Curtin University Postgraduate Scholarship and a Curtin Research Scholarship. He would like to thank Adjunct Professor John Simpson at the School of Economics and Finance, Curtin University, Bentley, for his comments and suggestions.

\section{References}

Amihud, Y., \& Mendelson, H. (1987). Trading Mechanisms and Stock Returns: An Empirical Investigation. Journal of Finance, 62, 533-553. http://dx.doi.org/10.1111/j.1540-6261.1987.tb04567.x

Barberis, N., Shleifer, A., \& Vishny, R. (1998). A model of investor sentiment. Journal of Financial Economics, 49, 307-343. http://dx.doi.org/10.1016/S0304-405X(98)00027-0

Chan, L.K.C., Jegadeesh, N., \& Lakonishok, J. (1996). Momentum strategies. Journal of Finance, 51, 1681-1713. http://dx.doi.org/10.1111/j.1540-6261.1996.tb05222.x

Conrad, J., \& Kaul, G. (1997). An anatomy of trading strategies. Review of Financial Studies, 11, 489-519. http://dx.doi.org /10.1093/rfs/11.3.489. 
Daniel, K.D., Hirshleifer, D., \& Subrahmanyam, A. (1998). Investor psychology and security market under- and overreactions. Journal of Finance, 53, 1839-1885. http://dx.doi.org/10.1111/0022-1082.00077

DeLong, J.B., Shleifer, A., Summers, L.H., \& Waldmann, R. (1990). Positive feedback investment strategies and destabilizing rational speculation. Journal of Finance, 45, 379-395. http://dx.doi.org/10.1111/j.1540-6261.1990.tb03695.x

Fama, E.F., \& French, K.R. (1993). Common risk factors in the returns on stocks and bonds. Journal of Financial Economics, 33, 3-56. http://dx.doi.org/10.1016/0304-405X(93)90023-5

Grossman, S.J., \& Miller, M.H. (1988). Liquidity and market structure. Journal of Finance, 43, 617-633. http://dx.doi.org/10.1111/j.1540-6261.1988.tb04594.x

Griffin, J., Ji, X., \& Martin, S. (2003). Momentum Investing and Business Cycle Risk: Evidence from Pole to Pole. Journal of Finance, 58, 2515-2547. http://dx.doi.org/10.1046/j.1540-6261.2003.00614.x

Grundy, B., \& Martin, J. (2001). Understanding the Nature of the Risks and the Source of the Rewards to Momentum Investing. Review of Financial Studies, 14, 29-78. http://dx.doi.org/10.1093/rfs/14.1.29

Hong, H., Lim, T., \& Stein, J.C. (1998). Bad news travels slowly: Size, analyst coverage and the profitability of momentum strategies. NBER working paper 6553.

Hong, H., Lim, T., \& Stein, J.C. (2000). Bad news travels slowly: Size, analyst coverage and the profitability of momentum strategies. Journal of Finance, 55, 265-296. http://dx.doi.org/10.1111/0022-1082.00206

Hong, H., \& Stein, J.C. (1999). A unified theory of under-reaction, momentum trading and overreaction in asset markets. Journal of Finance, 54, 2143-2184. http://dx.doi.org/10.1111/0022-1082.00184

Jegadeesh, N., \& Titman, S. (1993). Returns to buying winners and selling losers: Implications for stock market efficiency. Journal of Finance, 48, 65-91. http://dx.doi.org/10.1111/j.1540-6261.1993.tb04702.x

Jegadeesh, N., \& Titman, S. (2001). Profitability of Momentum Strategies: An Evaluation of Alternative Explanations. Journal of Finance, 56, 699-720. http://dx.doi.org/10.1111/0022-1082.00342

Kahnman, D., \& Tversky, A. (1979). Prospect Theory: an Analysis of Decision under Risk. Econometrica, 47, 263-291. http://dx.doi.org/10.2307/1914185

Korajczyk, R.A., \& Sadka, R. (2004). Are Momentum Profits Robust to Trading Costs? Journal of Finance, 59, 1039-1082. http://dx.doi.org/10.1111/j.1540-6261.2004.00656.x

Kyle, A.S. (1985). Continuous Auctions and Insider Trading. Econometrica, 53, 1315-1336. http://dx.doi.org/10.2307/1913210

Lesmond, D., Schill, M., \& Zhou, C. (2004). The Illusory Nature of Momentum Profits. Journal of Financial Economics, 71, 349-380. http://dx.doi.org/10.1016/s0304-405x(03)00206-x

Merton, R.C. (1987). A simple model of capital market equilibrium with incomplete information. Journal of Finance, 42, 483-510. http://dx.doi.org/10.1111/j.1540-6261.1987.tb04565.x

O'Hara, M. (2003). Presidential address: Liquidity and price discovery. Journal of Finance, 58, 1335-1354. http://dx.doi.org/10.1111/1540-6261.00569

Rouwenhorst, K.G. (1997). Local return factors and turnover in emerging stock markets. Working paper, Yale University.

Rouwenhorst, K.G. (1998). International momentum strategies. Journal of Finance, 53, 267-284. http://dx.doi.org/10.1111/0022-1082.95722

Wang, J. (1994). A model of competitive stock trading volume. Journal of Political Economy, 102, 127-168. http://dx.doi.org/10.1086/261924 